\title{
Finite Element Analysis and Parameter Optimization Selection of High Speed Milling GH4169
}

Guosheng Geng, Liang Zhang, Maohua Xiao, Xiayun Dong, Kailin Chen

College of Engineering, Nanjing Agricultural University, No.40, Dianjiangtai Road, Pukou Distinct, Nanjing 210031. China. Email: gsgeng@njau.edu.cn, 1323548442@qq.com, xiaomaohua@njau.edu.cn, 1054050268@qq.com,klchan12@foxmai.com

Nickel-based superalloy GH4169 has high strength and stability at high temperature and is widely used in aerospace and military fields. However, due to the problems of hard spots and poor thermal conductivity in actual processing, it is difficult for workers to select reasonable processing parameters during processing, which increases the difficulty of processing. In order to optimize the milling parameters,reduce the milling cost and operational difficulties in actual machining, we used ABAQUS finite element analysis software to simulate the 3D milling of GH4169 nickel base superalloy. The variation of milling force during milling was studied. The influences of milling speed, feed per tooth and radial depth on milling force were analyzed and the results of the simulation were compared with those obtained by orthogonal experiment. The variation of milling force was verified. Finally, we obtained the reasonable milling parameters.

Keywords: Nickel-based superalloy, ABAQUS finite element analysis, Milling force, Milling parameters

\section{Introduction}

GH4169 is a nickel-based superalloy composed of $\mathrm{Ni}-\mathrm{Cr}$ solid solution and Ni3nb and Ni3 (Al, Ti, Nb) as a strengthening phase.[1] GH4169 nickel-based superalloys have been widely used in the aerospace industry due to their high oxidation resistance, high strength and high corrosion resistance under high temperature conditions. It is mainly used to manufacture parts such as turbine blades and camshafts in aero engines[2-3]. However, in the actual processing, there are often problems such as tool wear, high workpiece temperature, work hardening and large cutting force, which affect the processing efficiency and precision[4-5]. It is one of the most difficult to process high temperature alloy materials.[6]

Ma et al.[7] used neural network genetic algorithm to predict residual stress in GH4169 nickel-based superalloy milling and optimized milling parameters. Liu et al.[8] used DEFORM-3D finite element software to analyze the milling force in GH4169 milling and verified the simulation results by single factor experiment and orthogonal experiment. LI et al.[9] used spectrum analysis to decouple the surface roughness into two parts: moving surface roughness and random surface roughness. They found that the moving surface roughness was affected by the tool and process, and the

$$
\bar{\sigma}=\left[A+B(\bar{\varepsilon})^{n}\right]\left[1+C \ln \left(\frac{\dot{\varepsilon}}{\dot{\varepsilon}_{0}}\right)\right]\left[1-\left(\frac{T-T_{\text {room }}}{T_{\text {meit }}-T_{\text {room }}}\right)^{m}\right],
$$

The Johnson-Cook model parameters of the random surface roughness was affected by the blade edge defect. Waseem Akhtar et al.[10] finished the GH4169 with a coated carbide insert and a whiskerenhanced ceramic insert, respectively and found that the surface integrity was best at minimum cutting feed rates and medium cutting speeds and depth of cut.

In order to explore the reasonable milling parameABAQUS finite element simulation analysis software to carry out three-dimensional modeling analysis of milling process. The effects of milling speed[11], feed per tooth and radial depth on the milling force were simulated and combined with experimental verification. The results will provide the basis for the selection of processing parameters.

\section{Constitutive model}

High-speed milling is a process of complex thermal dynamic coupling with a large amount of processing heat and material strain[12]. The Johnson-Cook[1314] constitutive model can more accurately reflect the work hardening, thermal softening, etc. of the material under high strain rate, large strain and high temperature conditions. The model is simple and applicable and the expression is:

GH4169 nickel-base superalloy were found in the material manual as shown in Tab. 1. ters of GH4169 nickel-based superalloy, we used 
Tab. 1 Johnson-Cook model parameters of GH4169 nickel base superalloy

\begin{tabular}{cccccc}
\hline Parameter & $\mathrm{A}$ & $\mathrm{B}$ & $\mathrm{n}$ & $\mathrm{C}$ & $\mathrm{m}$ \\
\hline $\begin{array}{c}\text { Numerical } \\
\text { value }\end{array}$ & $\begin{array}{c}450 \\
{[\mathrm{MPa}]}\end{array}$ & $\begin{array}{c}1700 \\
{[\mathrm{MPa}]}\end{array}$ & 1.3 & 0.017 & 0.65 \\
\hline
\end{tabular}

\section{Finite element analysis result}

\subsection{Milling force stress field distribution}

The finite element analysis parameters are shown in Tab. 2 below. The stress field distribution of the surface of GH4169 nickel-based superalloy material obtained by finite element analysis is shown in Fig. 1.

In the process of milling together with the main cutting edge and the minor cutting edge, the cutting edge of the material surface is most concentrated, which is equivalent to the first deformation zone, in which the material begins to fail.

Tab. 2 Finite element analysis parameter

\begin{tabular}{ccccc}
\hline & \multicolumn{4}{c}{ Factor } \\
\cline { 2 - 5 } N. & $\begin{array}{c}\text { Cutting } \\
\text { speed } \\
\text { A } \\
{[\mathrm{m} / \mathrm{min}]}\end{array}$ & $\begin{array}{c}\text { Radial } \\
\text { depth of } \\
\text { cut }\end{array}$ & $\begin{array}{c}\text { Feed per } \\
\text { B }[\mathrm{mm}]\end{array}$ & $\begin{array}{c}\text { Axial } \\
\text { depth of } \\
\text { Cut }\end{array}$ \\
\hline 1 & 60 & 0.4 & 0.04 & $\begin{array}{c}\mathrm{mm} / \mathrm{m}] \\
\text { D }[\mathrm{mm}]\end{array}$ \\
2 & 80 & 0.7 & 0.07 & 6 \\
3 & 100 & 1 & 0.1 & 6 \\
\hline
\end{tabular}
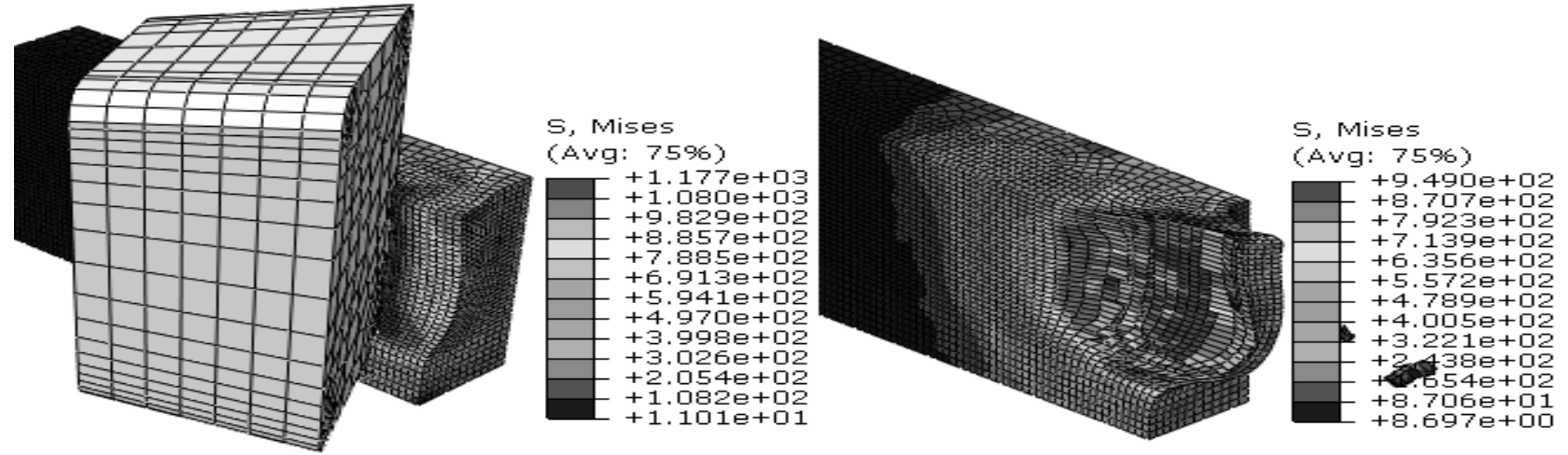

Fig. 1 Shear zone stress field distribution cloud map

\subsection{The change of milling force}

During the milling process, the tool is in periodic contact with the workpiece material, so the milling process is a periodic intermittent cutting process.In a milling cycle, the actual contact time of the tool with the workpiece material is very short ${ }^{15]}$. The tool gradually comes into contact with the material at the beginning of the machining and the milling force increases with the contact area. When the contact area between the blade and the material reaches the maximum, the friction of the rake face is maximized and the milling force reaches the maximum value. Then the tool and the chip gradually separate from the workpiece material and the milling force gradually reduces. At the same time, the cutting heat generates during the machining process causes the heat softening of the material so that the cutting force during the machining process reduces. Fig. 2 below shows the milling force variation curve for simulation analysis.

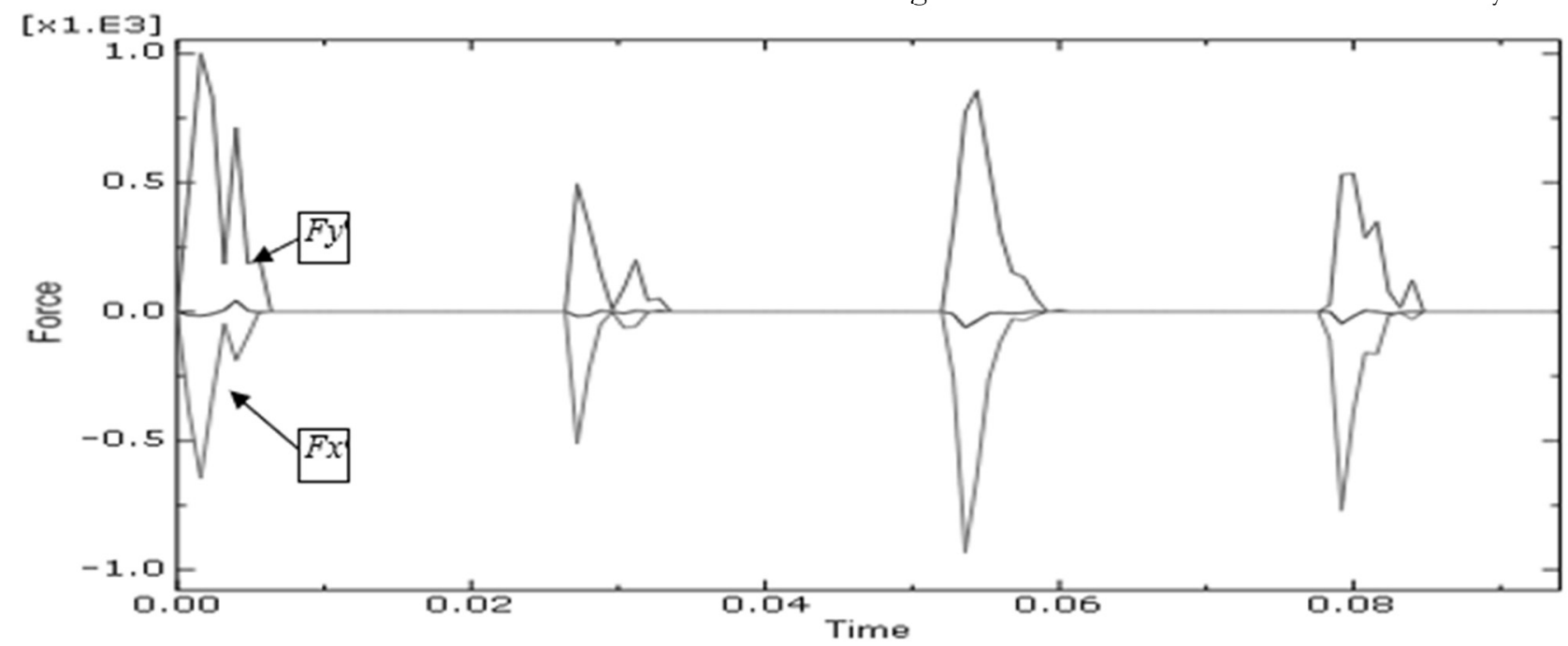

Fig. 2 Milling force change curve 
3.3 Influence of different milling parameters on milling force

The effect of milling speed on milling force

The effect of milling speed on milling forces is divided into two parts.In the first part, as the milling speed increases, the vibration and impact during milling increase and the milling force increases.In the second part, as the milling speed increases, the tempera-

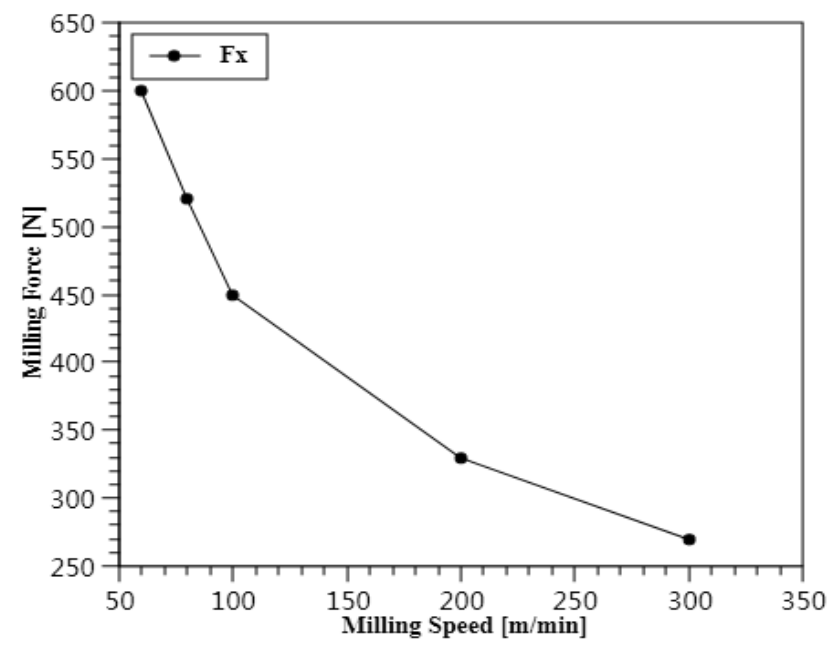

ture rises during the machining process and the thermal softening of the material causes the milling force to decrease ${ }^{[16-17]}$. The effect of milling speed on the milling force is shown in Fig. 3. The milling force generally decreases during the machining process. Therefore, as the milling speed increases, the influence of the reduction of milling force caused by thermal softening of the material is more obvious and the milling speed has a greater influence on Fx.

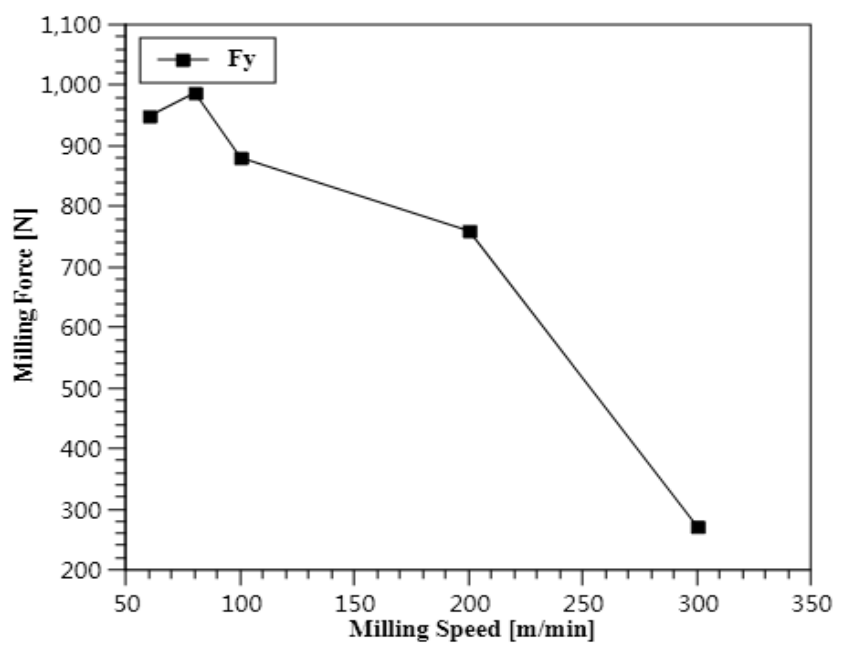

Fig. 3 The effect of milling speed on milling force

\section{The effect of feed per tooth on milling force}

As shown in Fig. 4 below, as the feed per tooth increases during the milling process, the instantaneous milling area will increase, resulting in an increase in the milling force Fx in the $\mathrm{X}$ direction. Meanwhile, as the

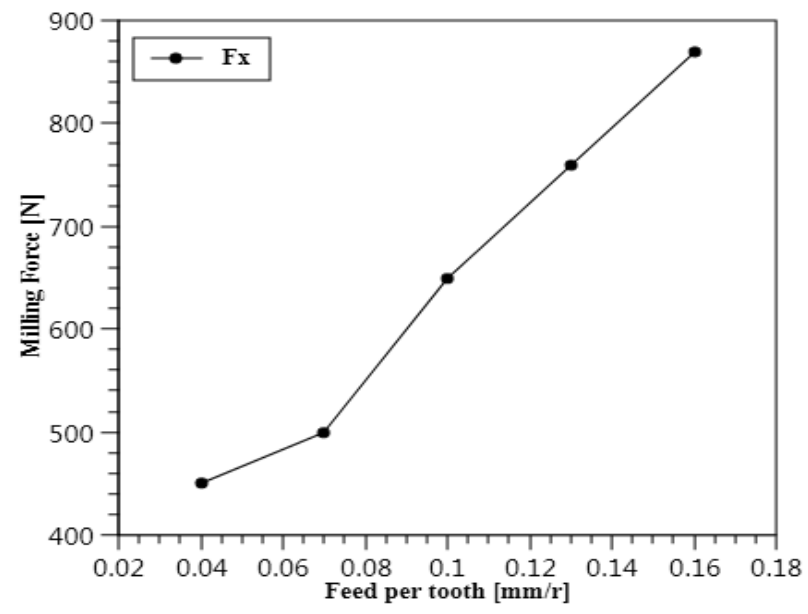

feed per tooth increases, the vibration and impact between the tool and the workpiece also increase, resulting in an increase in milling force. However the feed per tooth has less effect on the milling force in the $\mathrm{Y}$ direction.

Fig. 4 The effect of feed per tooth on milling force

The effect of radial depth of cut on milling force

During the milling process, as the radial depth of cut increases, the instantaneous milling area will increase, resulting in increased milling forces. As shown

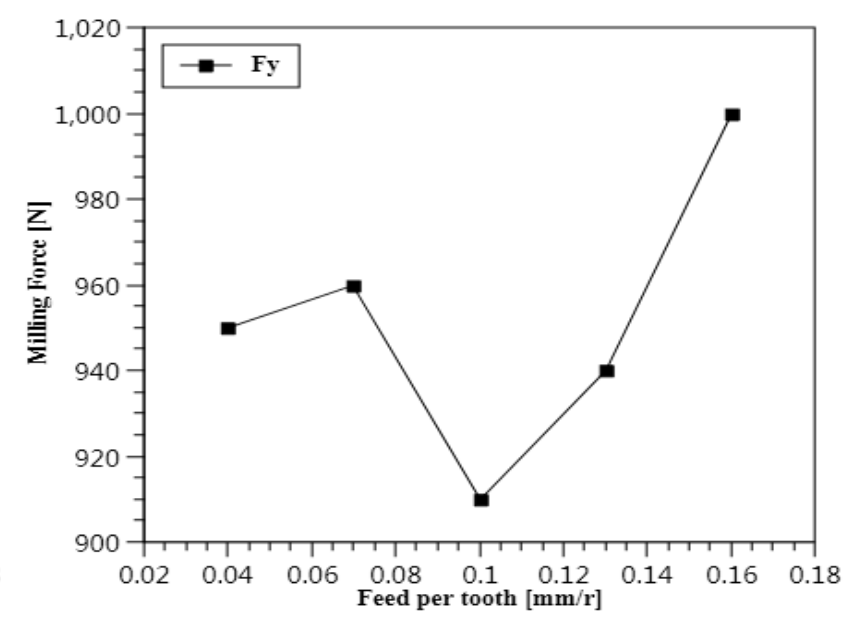

in Fig. 5 below, the increase in radial depth of cut increases the vibration and shock during milling, thus the radial force increases. The feed force Fx is less affected by the radial depth of cut and the degree of change is small. 

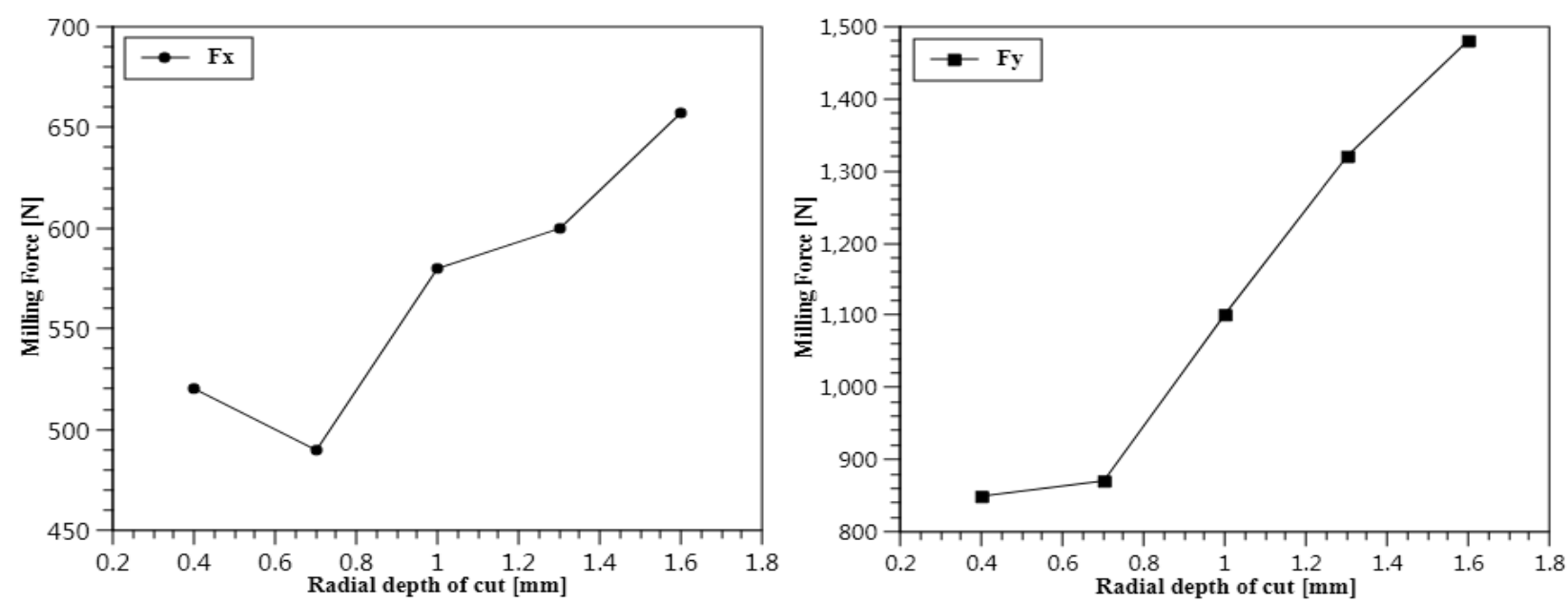

Fig. 5 The effect of radial depth of cut on milling force

\section{Milling experiment and analysis}

\subsection{Experiment apparatus}

The machine used for the milling experiment is: Mikron UCP710 five-coordinate high-speed machining center. The Kistler9265B dynamic force gauge with piezoelectric crystal sensor can measure the milling force in three directions during milling. The matched Kistler 5019 charge amplifier is used to amplify the acquired signal. The milling experiment was carried out with a carbide milling cutter produced by Seco Tools. The coating was F40M with a diameter of $25 \mathrm{~mm}$ and 3 teeth.

\subsection{Milling experiment research}

In order to save cost and improve accuracy, orthogonal experiments were used to study the effects of various cutting amounts. In order to accurately reflect the influence of the amount of processing used in actual production on the milling force, the milling experiment used three-factor and three-level experimental arrangements. Dry cutting and down milling were used in the experiment. Tab. 3 and 4 show the orthogonal experimental results and range analysis of the influence of processing amount on the feed force Fx and the radial force Fy, respectively.

Tab. 3 Orthogonal experimental results and range analysis of feed force $F x$

\begin{tabular}{|c|c|c|c|c|}
\hline \multirow{2}{*}{$\begin{array}{c}\text { Serial } \\
\text { number }\end{array}$} & \multicolumn{3}{|c|}{ Factor } & \multirow{2}{*}{$\begin{array}{l}\text { Feed force } \\
\text { Fx }[\mathrm{N}]\end{array}$} \\
\hline & $\begin{array}{l}\text { Cutting speed } \\
\text { A }[\mathrm{m} / \mathrm{min}]\end{array}$ & $\begin{array}{l}\text { Radial depth of cut } \\
\text { B }[\mathrm{mm}]\end{array}$ & $\begin{array}{l}\text { Feed per tooth } \\
\qquad \mathrm{C}[\mathrm{mm} / \mathrm{z}]\end{array}$ & \\
\hline 1 & 60 & 0.4 & 0.04 & 518.6 \\
\hline 2 & 60 & 0.7 & 0.07 & 533.5 \\
\hline 3 & 60 & 1 & 0.1 & 760.3 \\
\hline 4 & 80 & 0.4 & 0.07 & 465.2 \\
\hline 5 & 80 & 0.7 & 0.1 & 604.8 \\
\hline 6 & 80 & 1 & 0.04 & 493.8 \\
\hline 7 & 100 & 0.4 & 0.1 & 555.2 \\
\hline 8 & 100 & 0.7 & 0.04 & 332.8 \\
\hline 9 & 100 & 1 & 0.07 & 479.2 \\
\hline $\mathrm{T} 1$ & 1812.4 & 1539 & 1345.2 & \\
\hline $\mathrm{T} 2$ & 1563.8 & 1471.1 & 1477.9 & 4743.4 \\
\hline T3 & 1367.2 & 1733.3 & 1920.3 & \\
\hline $\mathrm{m} 1$ & 604.1 & 513 & 448.4 & \\
\hline $\mathrm{m} 2$ & 521.3 & 490.4 & 492.6 & \\
\hline $\mathrm{m} 3$ & 455.7 & 577.8 & 640.1 & \\
\hline $\mathrm{R}$ & 148.4 & 87.4 & 191.7 & \\
\hline
\end{tabular}


Tab. 4 Orthogonal experimental results and analysis of radial force Fy

\begin{tabular}{ccccc}
\hline \multirow{2}{*}{$\begin{array}{c}\text { Serial } \\
\text { number }\end{array}$} & $\begin{array}{c}\text { Cutting speed } \\
\text { A [m/min] }\end{array}$ & $\begin{array}{c}\text { Radial depth of cut } \\
\text { B [mm] }\end{array}$ & $\begin{array}{c}\text { Feed per tooth } \\
\text { C [mm/z] }\end{array}$ & $\begin{array}{c}\text { Radial force } \\
\text { Fy [N] }\end{array}$ \\
\hline 1 & 60 & 0.4 & 0.04 & 920.7 \\
2 & 60 & 0.7 & 0.07 & 910.7 \\
3 & 60 & 1 & 0.1 & 1045.4 \\
4 & 80 & 0.4 & 0.07 & 861.6 \\
5 & 80 & 0.7 & 0.1 & 940.9 \\
6 & 80 & 1 & 0.04 & 7164.1 \\
7 & 100 & 0.4 & 0.1 & 789 \\
8 & 100 & 0.7 & 0.04 & 1102.5 \\
9 & 100 & 1 & 0.07 & 8499.8 \\
T1 & 2876.8 & 2571.3 & 2849.7 & \\
T2 & 2966.6 & 2616.5 & 2874.8 & \\
T3 & 2656.4 & 3312 & 2775.3 & \\
m1 & 958.9 & 857.1 & 949.9 & \\
m2 & 988.9 & 872.2 & 958.3 & \\
m3 & 885.5 & 1104 & 925.1 & \\
R & 103.4 & 246.9 & 33.2 & \\
\hline
\end{tabular}

The relationship between the factors obtained by the range analysis and the feed force Fx and the radial force Fy (factor trend graph) is shown in Fig. 6.

According to the orthogonal experimental results of the feed force Fx, the order of the influence of each cutting amount factor on $\mathrm{Fx}$ is the feed per tooth $\mathrm{fz}>$ cutting speed $v>$ radial depth of cut aw. The feed rate per tooth, ie the feed rate, has the greatest influence on the feed force Fx and the Fx increases monotonically with the increase of the feed rate. The milling speed also has a large effect on Fx. The feed force Fx decreases monotonously with the increase of the cutting speed due to the thermal softening of the material caused by the increase in cutting speed. Radial depth of cut has less effect on Fx. The factor level that minimizes Fx is combined into A3B2C1, ie: $v=100 \mathrm{~m} / \mathrm{min}$, aw $=0.7 \mathrm{~mm}, \mathrm{fz}=0.04 \mathrm{~mm} / \mathrm{z}$.

According to the experimental results of the radial force $\mathrm{Fy}$, the order of the influence of each cutting amount factor on the radial force Fy is the radial depth of cut aw $>$ cutting speed $\mathrm{v}>$ feed per tooth $\mathrm{f} z$. The radial depth of cut has the greatest influence on the radial force, and Fy monotonically increases with the increase of the radial depth of cut. Because the radial force Fy is mainly caused by milling impact and vibration, the increase of the radial depth of cut will inevitably aggravate the milling vibration and impact. The milling speed also has a large influence on the radial force Fy. Fy increases first and then decreases with the increase of the milling speed. It is the result of the combined effect of the milling speed on the cutting force. The feed per tooth $\mathrm{fz}$ has a small effect on the radial force Fy. The factor level that minimizes Fy is combined into A3B1C3, ie: $\mathrm{v}=100 \mathrm{~m} / \mathrm{min}$, aw $=0.04 \mathrm{~mm}, f_{z}=0.1 \mathrm{~mm} / \mathrm{z}$.

Considering the influence of each cutting amount on Fx and Fy, the milling speed has a great influence on both. The higher milling speed is beneficial to reduce the milling force, but the cutting speed is limited by the tool life.Taking into account the tool life and cutting force factors, $60 \sim 80 \mathrm{~m} / \mathrm{min}$ is a reasonable milling speed. Considering the influence of tool durability, Fx and Fy, the reasonable cutting amount for milling GH4169 is:milling speed $\mathrm{v}=60 \sim 80 \mathrm{~m} / \mathrm{min}$, radial depth of cut aw $=0.7 \mathrm{~mm}$, feed per tooth $\mathrm{fz}=0.07 \mathrm{~mm} / \mathrm{z}$. 


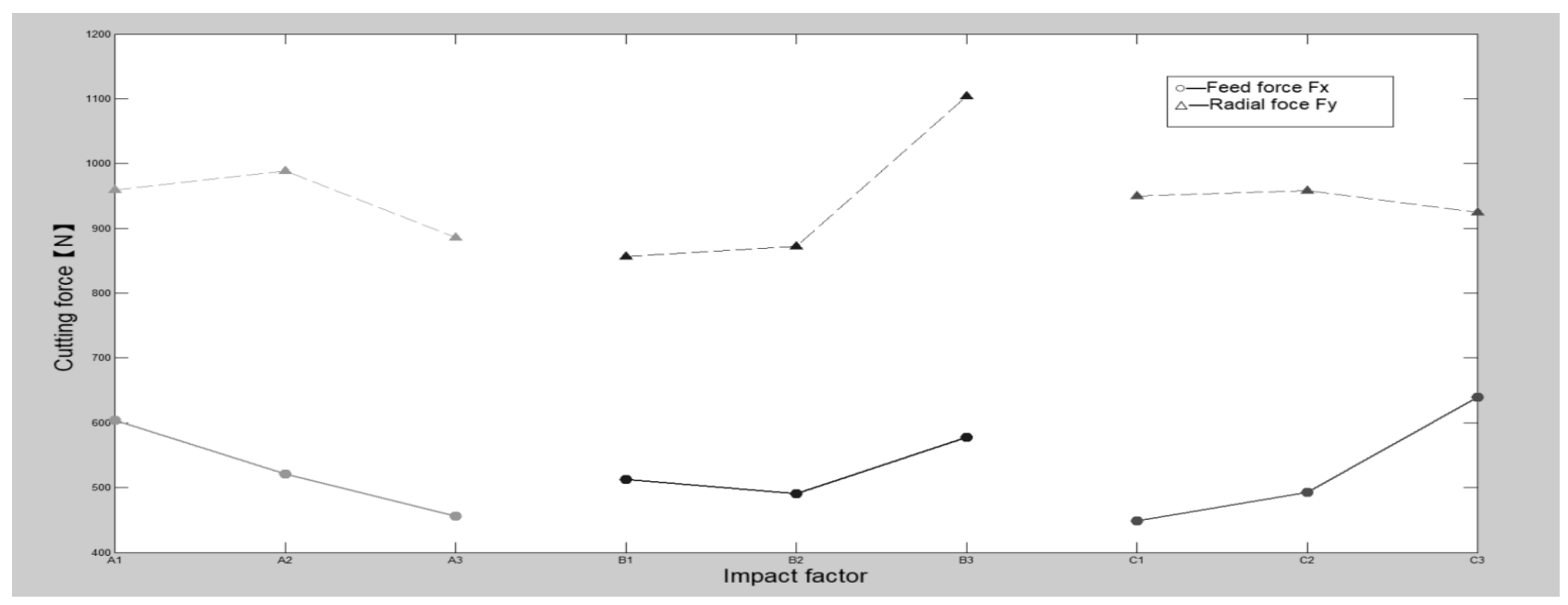

Fig. 6 Relationship between various factors and feed force Fx and radial force Fy

\subsection{Comparative analysis}

According to Fig. 3-6, the simulation law that the milling force is affected by the cutting speed, the radial depth of cut and the feed per tooth is consistent with the experimental law. We compared the simulation results with the cutting force data of the 1,4 and 7 groups in the orthogonal experiment (as shown in Fig. 7) and the values of the cutting force in the simulation

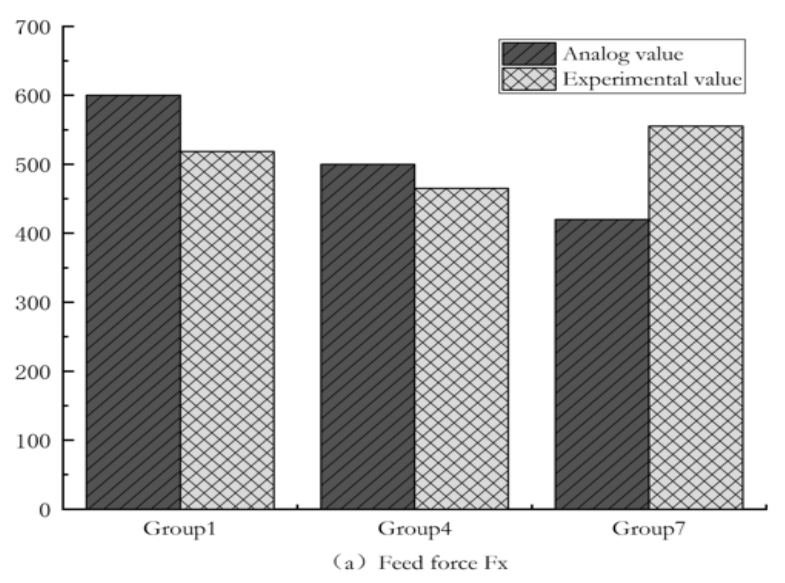

and experimental results were largely deviated. The error between the values is due to the simplification of the model and the inaccuracy of the material parameters in the simulation. At the same time, the vibration of the machine tool, the wear of the tool and other factors that are not considered in the experiment may make the results different. So we can use the simulation method to study some regular problems in the milling process and also predict the actual milling force based on the error compensation.

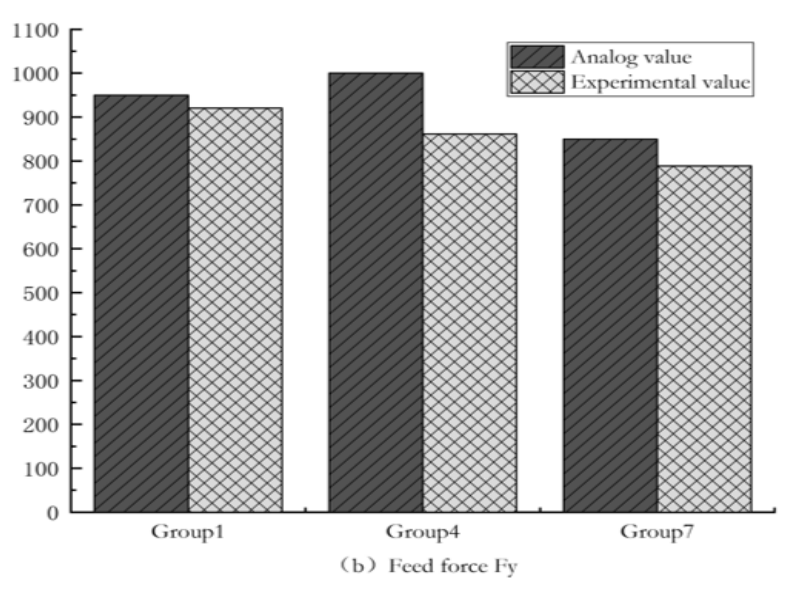

Fig. 7 Comparison of milling force simulation results and test results

\section{Conclusions}

By using ABAQUS finite element simulation analysis software, the effects of milling speed, feed per tooth and radial depth of cut on the milling force were studied and verified by experiments. The conclusions are as follows:

(1) The increase in milling speed leads to a reduction in the milling force, in which the thermal softening of the material dominates and the change in the milling force in the $\mathrm{X}$ direction is particularly pronounced.
(2) The increase in the feed per tooth leads to an increase in the instantaneous milling area, so the milling force increases, but the milling force in the $\mathrm{Y}$ direction is less affected.

(3) Properly reducing the radial depth of cut can reduce the vibration and impact during milling and reduce the milling force, but has less effect on the variation of milling force in the $\mathrm{X}$ direction.

(4) The most reasonable parameters for milling GH4169 are: milling speed $\mathrm{v}=60 \sim 80 \mathrm{~m} / \mathrm{min}$, radial depth of cut aw $=0.7 \mathrm{~mm}$, feed per tooth $\mathrm{fz}_{\mathrm{z}}=0.07$ $\mathrm{mm} / \mathrm{z}$. 


\section{Acknowledgment}

The research is funded partially by the Agricultural Science and Technology Independent Innovation Fund of Jiangsu Province (CX(19)3081) and the Key Research and Development Program of Jiangsu Province (BE2018127).

\section{References}

[1] GAO, D.Q., Ding, X., YANG, R.D., WANG, J.J. (2019). Finite Element Simulation and Analysis of High Speed Cutting GH4169 Nickel Base Alloy. In: Tool Technology, Vol. 53, No. 1, pp. 105-109. ISSN 1000-7008.

[2] ZHANG, C.Y., REN, H., REN, J.L., YUAN, D.P., GUAN, X.Y. (2011). Study on Cutting Performance of Nickel-Based Alloy Steel Based on DEFORM-3D. In: Journal of Jiangsu University of Science and Technology (Natural Science Edition), Vol. 25, No. 4, pp. 350 -353. ISSN 1673-4807.

[3] PENG, R.T., LIAO, M., TAN, Y.Q., LIU, X.W. (2012). Experimental Study on Prestressed Cutting Nickel Base Superalloy. In: Journal of Mechanical Engineering, Vol. 48, No. 19, pp. 186-191. ISSN 0577-6686.

[4] XIAO, M., SUN, Z., SHEN, X., SHI, L., ZHANG, J. (2019). Research on 3D Reconstruction Technology of Tool Wear Area. In: Manufacturing Technology, Vol. 19, No. 2, pp. 345349. ISSN 1213-2489.

[5] KUNDRÁK, J., \& PÁLMAI, Z. (2019). The Change of Tool Life in a Wide Range of Cutting Speeds in Hard Turning. In: Manufacturing Technology, Vol. 19, No. 2, pp. 254-260. ISSN 12132489.

[6] LOULOVA, M., SUCHANEK, A., HARUSINEC, J. (2017). Evaluation of the parameters affecting passenger riding comfort of a rial vehicle. In: Manufacturing Technology, Vol. 17, No. 2, pp. 31-49. ISSN 1213-2489.

[7] ZHAO, Z. Y., LI, L., TAN, L., BAI P. K., LI, J., WU, L. Y., LIAO, H.H., CHENG, Y. H. (2018). Simulation of Stress Field during the Selective Laser Melting Process of the NickelBased Superalloy, GH4169. In: Materials, Vol. 11, No. 9. ISSN 1996-1944.

[8] MA, S.L., DONG, C.S. (2018). Analysis and Prediction of Surface Residual Stress of Micro Milling Superalloy GH4169.In: Tool Technology, Vol. 52,No. 4, pp. 79-82. ISSN 1000-7008.
[9] BITTNER, V., TUCEK, R., PANSKA, S., SVOBODA, M., IELEN, K. (2017). Using the fourier transform in the analysis of vibration load tests of heterogeneous mechanical systems. In: Manufacturing Technology, Vol. 17, No. 6, pp. 836-841. ISSN 1213-2489.

[10] LIU, J.Q., ZHAO, H.K., FENG, L.L., LI, F. (2015). Finite Element Simulation and Milling Force Test Analysis of Milling Process of Superalloy GH4169. In: Journal of Xi'an University of Technology, Vol. 35, No. 6, pp. 441-446. ISSN 1673-9965.

[11] KUNDRÁK, J., MARKOPOULOS, A.P., MAKKAI, T., KARKALOS, N.E. (2019). Effect of Edge Geometry on Cutting Forces in Face Milling with Different Feed Rates. In: $M a-$ nufacturing Technology, Vol. 19, No. 6, pp. 984992. ISSN 1213-2489.

[12] LI, X., GUAN, C.M., ZHAO, P. (2018). Influences of milling and grinding on machined surface roughness and fatigue behavior of GH4169 superalloy workpieces. In: Chinese Journal of Aeronautics, Vol. 31, No. 6, pp. 1399-1405. ISSN 1000-9361.

[13] AKHTAR, W., SUN, J. F., CHEN, W. Y. (2016). Effect of Machining Parameters on Surface Integrity in High Speed Milling of Super Alloy GH4169/Inconel 718. In: Materials and Manufacturing Processes, Vol. 31, No. 5, pp. 620627. ISSN 1042-6914.

[14] PENG, C.X., WU, Y.X., YI, S.H., GONG, H. (2018). Study on the Influence of JC Constitutive Model on 2D Cutting Simulation of 7050 Aluminum Alloy. In: Tool Technology, Vol. 52, No. 11, pp. 59-62. ISSN 1000-7008.

[15] JOHNSON,G.R., COOK.W.H. (1985). Fracture characteristics of three metals subjected to various strains, strain rates, temperatures and pressures. In: Engineering Fracture Mechanics. Vol. 21, No. 1, pp. 31-48. ISSN 0013-7944.

[16] JOHNSON, G.R., HOLMQUIST.T.J.(1988). Evaluation of cylinder-impact test data for constitutive model constants. In: Journal of Applied Physics. Vol. 64, No. 8, pp. 3901-3910. ISSN 0021-8979.

[17] CHALUPA, M., VEVERKA, J. (2016). Handling simulation of vehicles. In: Manufacturing Technology, Vol. 16, No. 6,pp. 1269-1274. ISSN 1213-2489. 